\title{
Subsidiary Entities and the Innovator's Dilemma
}

\author{
Kenneth Ayotte \\ Northwestern University School of Law \\ November 2011 \\ Very preliminary-not for general distribution
}

\begin{abstract}
An influential theory in the management literature (Christensen, 1997) argues that incumbent firms have difficulty commercializing innovations that are not initially useful to its existing customers, and recommends creating separate, autonomous units for the innovation. This paper explains why subsidiary entities, even when wholly-owned and formally controlled by their corporate parent, can assist in this process. I show that placing the innovation in a subsidiary creates more autonomy for the unit manager of the innovation than if the same project were held as a division inside the parent entity.

The key difference between subsidiaries and divisions in my model is limited liability: unlike a division, the parent has the option to walk away from the subsidiary's obligations. Because of this implicit "put option", the parent invests less in developing internal uses for the innovation. This causes the unit manager to invest more in developing independent uses for the innovation, for two reasons. First, less investment by the parent means the unit manager must "sink or swim" on the product of his own effort. Second, less parent involvement means that the unit manager's desired actions are less subject to overrule. This increases the unit manager's initiative, as in Aghion and Tirole (1987).
\end{abstract}




\section{Introduction}

Most large firms are comprised of many subsidiary legal entities. These sub-entities are often, partially or fully, owned and controlled by a corporate parent. While there are many reasons for the proliferation of subsidiaries, the goal of this paper is to study their use as a mechanism for encouraging innovation from within an existing firm. Subsidiaries are often used to house innovative projects: Chesbrough (2003) studies 35 separate legal entities created by Xerox between 1984 and 1998 to commercialize output from their research laboratories. Some of these entities succeeded and went public, others were reabsorbed by Xerox, and some failed and were liquidated in bankruptcy.

A prominent theory in the management literature (Christensen 1997, Christensen and Raynor 2003) argues that separate business units can help to solve the "innovator's dilemma" that incumbent firms face when a new technology appears in a marketplace. Historically, incumbent firms have been particularly unsuccessful in commercializing disruptive innovations that are not immediately useful to a firm's existing customers. Creating separate business units, the theory argues, gives the management of these units more autonomy to pursue new markets for the innovation and to attract new customers. Absent this separation, the firm is prone to failure, as the incumbent tends to "cram" the innovation into its existing business model, channeling it to the needs of only its existing customers, and relying on its existing corporate resources to commercialize it.

Though Christensen (1997) notes several examples of established firms creating separate units for disruptive innovations successfully, this work is less clear about whether legal separation-the creation of a separate subsidiary entity to house the innovation- is required to create autonomy. IBM's successful unit that developed the PC, for example, was physically separated from the company's headquarters by locating it in Florida, but the unit's assets were held legally as a division of IBM, not as a subsidiary. Dayton Hudson, by contrast, set up the discount retailer Target Corporation as a wholly-owned subsidiary corporation. The management literature to date has not attempted to explain whether separate legal entities help to create autonomy, the mechanism by which this might work, and the circumstances under which a project inside an existing firm should be held as a division, placed into a separate subsidiary, or sold/spun off completely.

This model demonstrates that placing a business unit in a separate subsidiary entity, even if it is wholly-owned and controlled by its parent, can be a useful tool to create more autonomy for unit managers. The intuition is quite simple, and follows from the seminal work on formal

and real authority by Aghion and Tirole (1997), as well as the property rights theory of 
Grossman and Hart (1986). Placing assets in a subsidiary limits the parent's exposure on the subsidiary's debts to the value of the subsidiary's assets. This gives the parent a valuable "put option": it can allow the subsidiary to default on these debts and limit the creditors' recovery to the value of the subsidiary's assets. This implies that the net loss to the parent when the project assets lose value is smaller than if the project were run as a division inside the parent entity.

Given that subsidiaries change the parent's payoff structure, the unit manager rationally anticipates that the parent will invest less in developing uses for the subsidiary's assets its existing business. This gives the unit manager stronger incentives to develop independent uses for the innovation, for two reasons. First, less parent investment implies a greater likelihood of default and liquidation of the project assets, unless the unit manager's effort in commercializing the innovation succeeds. If the unit manager's value to the firm is tied to the value of the assets, he runs a greater downside risk when the parent invests less. Thus subsidiaries, relative to divisions, create a stronger "sink or swim" effect for the unit manager, which increases his incentive to succeed with the new venture. This may ultimately benefit the parent through its ownership stake in the venture.

Second, the unit manager gains independence in a subsidiary, which increases his initiative. His decisions will be less subject to the interference that might occur when the unit manager and the parent have competing uses in mind for the assets. Thus, the unit manager devotes more effort to making the new project succeed on its own. In the language of Aghion and Tirole, the unit manager gains more real authority when his project is spun into a subsidiary, despite no (necessary) change in his formal authority. This "independence effect" is only salient when the parent will prefer to overrule the unit manager-this occurs when the parent's potential payoff from an internal use of the assets is larger than the parent's potential payoff from an independent use. Thus, the model supports an intuition in Christensen (1997), that separation (here, through subsidiary entities) is particularly important for creating incentives to commercialize small projects inside large firms. ${ }^{1}$

At the same time, a subsidiary may prove a better option than selling (or spinning off) the project at the outset. Though a sale of a project provides even greater autonomy and even stronger "sink or swim" incentives to the unit manager than a subsidiary, the subsidiary has the advantage that it can be reabsorbed by the parent if the new unit's project fails. If it

\footnotetext{
${ }^{1}$ The small size problem, according to Christensen (1997), "argues for a policy of implanting projects to commercialize disruptive innovations in small organizations that will view the projects as being on their critical path to growth and success, rather than as being distractions from the main business of the company."
} 
chooses to pay off the subsidiary's obligations and bringing the innovative assets back inside the firm, the parent can realize some value from any investments made in internal uses for the assets if the stand-alone project fails. If the project is sold/spun off, by contrast, the parent would need to repurchase the assets from the buyer to make use of them, which subjects the parent to a holdup problem (Grossman and Hart 1986). Thus, the model rationalizes the intuition that subsidiaries can serve as laboratories for experimentation, because they provide independence in a way that minimizes the negative consequences of failure (Harford, 2011). ${ }^{2}$

\section{Model}

\section{$2.1 \quad$ Timeline}

The model is in the spirit of Aghion and Tirole (1987), with the presence of assets that are necessary to realize the value of specific investments, as in Grossman and Hart (1986). It takes place over four dates, $0, \frac{1}{2}, 1$, and 2 . At date 0 , a parent firm, owned and run by a principal $(\mathrm{P})$, is endowed with two assets (call them $\mathrm{X}$ and $\mathrm{Y}$ ), and two projects: an existing project, and a new project. The existing project requires asset $\mathrm{Y}$, and the management of $\mathrm{P}$ : this is intended to represent the parent's "core" business. The new project, unless liquidated, always requires the management of a wealthless agent $(\mathrm{A})$ and asset $\mathrm{X}$. But the project may prove to be more valuable with both $\mathrm{X}$ and $\mathrm{Y}$, depending on the value of investments made by $\mathrm{P}$ and $\mathrm{A}$. If the new project uses only asset $\mathrm{X}$, we will call the project "independent" from its parent. If the project uses both $\mathrm{X}$ and $\mathrm{Y}$, we will call the project "internal". Asset Y could be a tangible asset, like a production facility, or an intangible asset, like customer relationships or human capital in the firm's marketing and sales forces. Asset X can also be tangible or intangible, as long as it is alienable; that is, it must be an asset that can be pledged and seized by a creditor, and re-sold. ${ }^{3}$

Alternatively, let $L$ denote the best possible use of asset $\mathrm{X}$ that does not require $\mathrm{P}, \mathrm{A}$ or Y. $L$ can be seen as a termination of the project and a reallocation of asset $\mathrm{X}$ to a new use. The choice to use asset $\mathrm{X}$ internally, independently, or in liquidation is mutually exclusive.

\footnotetext{
${ }^{2}$ The intuition herein, however, is different from the standard intuition, that the failure of a large division might cause the parent to fail, and subsidiaries can prevent this. We discuss this possibility in the extensions, but the main mechanism in this paper does not rely on the innovative unit and its debts being so large that it can cause the parent firm to default.

${ }^{3}$ In many cases, $\mathrm{X}$ could be human capital assets (employees) as long as these employees sign long-term contracts that can be transferable to a new owner or creditor.
} 
The mutual exclusivity of internal and independent use is an important element of the model. This might occur because a scarce resource, like a sales force, must be deployed to sell the product to existing customers or try to recruit new customers. Similarly, engineers might be required to adapt the product to the needs of the target customers. This may make it costly to pursue independent and internal uses for the product at the same time.

$\mathrm{P}$ must decide on the legal and financing structure of the new project at date 0 . At date $\frac{1}{2}$, the new project and parent project managers make non-contractible investments in information, to decide how to best use the assets in production. At date 1, the value of the investments are realized, debts may come due, and assets can be reallocated. At date 2, projects produce a final cash flow.

\subsection{Projects, investments, and cash flows}

The date 2 cash flow from the existing project is assumed to be a certain, large value, provided that asset $\mathrm{Y}$ is owned by $\mathrm{P}$ through date 2. The date 2 cash flow from the new project is uncertain. Its value will depend on the information generated by $\mathrm{P}$ and $\mathrm{A}$, and how the assets are used. Following Aghion and Tirole, we suppose there are several possible action choices for the new project, whether run independently or internally. For either use, we suppose that one of the action choices produces a large, negative payoff for both $\mathrm{P}$ and $\mathrm{A}$, so that both $\mathrm{P}$ and $\mathrm{A}$ would prefer liquidation to choosing an action at random without information.

We suppose that the investments in information by $\mathrm{P}$ and $\mathrm{A}$, if successful, reveal all possible uses for asset $\mathrm{X}$. The possible uses include an internal action for asset $\mathrm{X}$ with value $y$, and an independent use with value $x$. The liquidation value $L$ is fixed and known in advance. We suppose that $L<x, y$. We assume that the liquidation event is contractible, but the decision to make the new project internal or independent is not verifiable, nor is the value of the project ( $x$ or $y$ ) verifiable, as long as asset $\mathrm{X}$ is owned by $\mathrm{P}$. The degree to which a business unit relies on its corporate parent's assets is unlikely to be contractible in practice. Moreover, the assumption that the cash flows produced by the project is noncontractible reflects the fact that a parent can easily, through transfer pricing, tunneling, or other means, make misleading reports about the cash flows of a unit it controls. The assumption of limited verifiability leads to the optimality of debt contracts, because it implies that an investor must rely on the threat to seize project assets in order to be repaid, as in Bolton and Scharfstein $(1990,1996)$ and Hart and Moore (1994). 


\subsection{Preferences}

P derives linear utility from monetary wealth, but incurs a private cost of seeking information. If $\mathrm{P}$ chooses effort level $E$, she becomes informed with probability $E$, and incurs a cost $g_{p}(E)=\frac{1}{2} c E^{2}$. Hence, her utility if she chooses effort level $E$ and receives monetary payoff $\pi_{p}$ is $U_{p}=\pi_{p}-\frac{1}{2} c E^{2}$.

In the simplest specification of the model, I follow Aghion and Tirole in assuming that A derives utility only from the private, non-monetary benefits of running a project, and does not respond to monetary incentives. (We will consider incentive compensation later in the paper). The private benefit can be interpreted as intrinsic motivation, or as a reputational benefit. The lack of response to monetary incentives can be seen as a strong form of risk aversion by $\mathrm{A}$.

Let $B$ represent A's private benefit from independence, $b$ from internal management, and 0 from liquidation. I assume that $B>b \geq 0$ : $\mathrm{A}$ is assumed to strictly prefer managing an independent project to being a division manager of an internal project, and he weakly prefers managing a project in some form to liquidation. Information gathering is also costly to the agent, so if A chooses effort level $e$, he discovers a valuable action with probability $e$ and incurs the cost $g_{a}(e)=\frac{1}{2} d e^{2}$. Hence, A's utility function is given by $U_{a}=\beta-\frac{1}{2} d e^{2}$ where $\beta=\{B, b, 0\}$ is his private benefit from the action chosen at date 1 .

To ensure interior solutions for effort by $\mathrm{P}$ and A, I assume that the effort cost functions are sufficiently convex: namely, $c>y-L$ and $d>B$.

\subsection{The organizational structure decision}

At date 0, the parent firm can choose one of four organizational structures for the new project: a division, a parent-controlled or agent-controlled wholly-owned subsidiary, or a sale of asset $\mathrm{X}$ to a new owner. ${ }^{4}$ Given the assumption that unit cash flows are not separately verifiable, partially-owned subsidiaries are never optimal in this framework. Also, given that courts are generally reluctant to enforce contracts within firm boundaries, I assume that A can not be given formal control of an asset owned by $\mathrm{P}$ unless $\mathrm{P}$ creates a subsidiary entity and transfers assets into it. ${ }^{5}$ Note, however, that if a subsidiary is created, $\mathrm{P}$ can choose whether $\mathrm{P}$ or A has legal control rights over the assets in that subsidiary.

\footnotetext{
${ }^{4} \mathrm{~A}$ sale is similar to a spinoff, in that control over project assets are separated from the parent. Our model does not distinguish between the two, and we will consider them equivalent here.

${ }^{5}$ This is not crucial. A division that the agent controls is equivalent to an A-sub with debt less than or equal to the liquidation value of the assets.
} 
The difference between a division and a parent-controlled wholly-owned subsidiary is driven entirely by the differential rights of creditors in the two organizational forms. If $\mathrm{P}$ chooses a divisional structure, then the parent is responsible for the project's debts. The parent will maintain control rights over assets $\mathrm{X}$ and $\mathrm{Y}$ through date 2 as long as she repays her creditors at date 1; if she does not, the creditor can seize either asset to repay the debt. (Since we assume that project $\mathrm{E}$ generates a large cash flow which requires asset $\mathrm{Y}, \mathrm{P}$ will always choose to repay any debts that place asset $\mathrm{Y}$ at risk of seizure). If, instead, $\mathrm{P}$ places asset $\mathrm{X}$ in a subsidiary and issues debt at the subsidiary level, then $\mathrm{P}$ might choose to default at date 1 and lose only asset $\mathrm{X}$. As with divisions, the parent can retain control of asset $\mathrm{X}$ through date 2 as long as the subsidiary's creditor is repaid.

The difference between the agent and principal-controlled wholly-owned subsidiary (call these A-sub and P-sub for short) is the control right over use of asset $\mathrm{X}$. In a $\mathrm{P}$-sub, $\mathrm{P}$ has formal, legal control over the use of asset $\mathrm{X}$. Hence, if both $\mathrm{P}$ and $\mathrm{A}$ discover a use for asset $\mathrm{X}, \mathrm{P}$ will choose the action that maximizes her monetary payoff in a $\mathrm{P}$-sub. In practice, the subsidiary would be a $\mathrm{P}$-sub if $\mathrm{P}$ controlled the board of directors of a corporation managed by A: by doing so, $\mathrm{P}$ could simply replace $\mathrm{A}$ and take control of the decision rights over the assets in the sub. Conversely, in an A-sub, A will choose the action that maximizes his private benefit when both parties have information. $\mathrm{P}$ could create an A-sub by giving $\mathrm{A}$ control that $\mathrm{P}$ could not revoke at will. For example, $\mathrm{P}$ could give $\mathrm{A}$ shares in the sub with high-powered voting rights, so that $\mathrm{P}$ could not easily replace $\mathrm{A}$.

Finally, if the parent chooses a sale, asset $\mathrm{X}$ is sold to a new owner. The parent can only acquire control over the project asset by repurchasing it at date 1 . I will assume that the date 0 buyer has the bargaining power in a negotiation with $\mathrm{P}$ over control of asset $\mathrm{X}$ at date 1; this division of bargaining power is not essential to the model: it merely highlights the effect of a holdup problem in the most transparent way.

We will now analyze the parent's decision problem over the four possible organizational forms (division, sale, principal-controlled and agent-controlled subsidiary). The game between $\mathrm{P}$ and $\mathrm{A}$ depends importantly on whether $\mathrm{A}$ expects to be overruled by $\mathrm{P}$ when both parties have valuable information. Thus, we consider these two cases separately. In the first case, where A's project has a larger payoff than P's project conditional on success, no interference by $\mathrm{P}$ will occur, but the organizational form can still have important effects on incentives. After considering this case, we will consider the small-payoff project, in which subsidiaries can create greater independence for A. 


\subsection{The large-payoff project $(x>y)$ : the parent's problem}

\subsubsection{Divisions}

If the parent chooses to keep the project as a division of the existing firm, then no debt is issued. Given that $\mathrm{P}$ owns asset $\mathrm{X}$ already, she need not seek out new financing. P's date $\frac{1}{2}$ problem is to choose her effort level $\mathrm{E}$ to maximize

$$
\max _{E} U_{p} \equiv E(1-e)(y-L)+e(x-L)+L-\frac{1}{2} c E^{2}
$$

The agent, meanwhile, solves the following problem:

$$
\max _{e} E(1-e) b+e B-\frac{1}{2} d e^{2}
$$

The first order conditions for $\mathrm{P}$ and $\mathrm{A}$ are, respectively,

$$
\begin{aligned}
E & =\frac{(1-e)(y-L)}{c} \\
e & =\frac{B-E b}{d}
\end{aligned}
$$

As in Aghion and Tirole, these "reaction curves" for P and A are negatively sloped. In other words, P's optimal effort decreases in A's effort, and vice versa.

\subsubsection{Sale}

If asset $\mathrm{X}$ is sold at date 0 , a buyer would pay the expected value of becoming the owner/principal of asset $\mathrm{X}$ and hiring $A$ to manage it. Since we assume that the buyer has all the bargaining power in negotiations with $P$ at date $1, P$ would be subject to a holdup problem. If she acquired information that would make the value of asset $\mathrm{X}$ worth $y$, the date 0 buyer would offer to sell the asset for a price of $y$. The inability to capture any surplus from her effort reduces her effort to zero. Hence, $E$ is always 0 after a sale. Thus, we only need solve for the sale price that the buyer is willing to pay, which is based on the buyer's expectation of A's choice of $e$.

Knowing that $E=0, A$ 's problem is simply

$$
\max _{e} e B-\frac{1}{2} d e^{2}
$$

Inspection of A's problem, in comparison to her maximization problem under divisions, makes it evident that a sale provides the strongest incentives for the agent. Since P's effort is 
always zero, A receives a payoff if and only if he generates information. Under divisions, by contrast, he receives the expected payoff $E b$ if he generates no information. The first order condition for A's optimal effort choice is

$$
e_{\text {sale }}=\frac{B}{d}
$$

and the date 0 sale price of asset $\mathrm{X}$, which is also P's profit, is:

$$
U_{p}=\frac{B}{d}(x-L)+L
$$

\subsubsection{Subsidiary}

If the project is a large-payoff project, then the objectives of $\mathrm{P}$ and $\mathrm{A}$ are congruent. This implies that control rights over the subsidiary's assets does not matter: whenever both $\mathrm{P}$ and A have information, independence is preferred by both; similarly, both prefer that an action is taken when one party has information and the other does not. This implies that an A-sub is equivalent to a P-sub. If the parent chooses to place the firm in a (wholly-owned) subsidiary, then the date 0 problem requires choosing $\mathrm{F}$ and $\mathrm{K}$ to solve the following problem:

$$
\max _{F, K} E(1-e)(y-F)^{+}+e(x-F)^{+}+(1-e)(1-E)(L-F)^{+}-\frac{1}{2} c E^{2}+K
$$

where $F$ is the face value of the debt issued to the outside investor at date $0 . K$ is the cash proceeds of the debt issuance, which are paid to $\mathrm{P}$ at date 0 . $\mathrm{P}$ 's maximization problem can be simplified slightly. First, we can restrict consideration to $F>L$ without loss of generality: it is easy to show that divisions are equivalent to subsidiaries whenever $\mathrm{P}$ has no incentive to default; i.e. whenever $F \leq L$. It is also straightforward to show that a sale would be equivalent to a subsidiary when $F \geq y$ : if $F \geq y$, then $\mathrm{P}$ would choose to default whenever she has information and A does not. ${ }^{6}$ Due to the holdup problem that would result, P's effort falls to zero, and A's problem would be the same as if asset $\mathrm{X}$ were sold. Hence, we can restrict consideration to $L<F<y$. Thus P's date 0 problem reduces to:

$$
\max _{F, K} U_{p}=E(1-e)(y-F)+e(x-F)-\frac{1}{2} c E^{2}+K
$$

\footnotetext{
${ }^{6}$ In reality, one would expect that deadweight bankruptcy costs would be incurred when a subsidiary defaults. If these costs were positive, a subsidiary with $F>y$ would be strictly inferior to a sale. We discuss bankruptcy costs later in the paper.
} 
The maximization is subject to incentive compatibility (IC) constraints for effort by the principal and agent at date $\frac{1}{2}$, and the investor's date 0 participation constraint. The IC constraints for $\mathrm{P}$ and $\mathrm{A}$ are, respectively:

$$
\begin{aligned}
E & =\arg \max E(1-e)(y-F)+e(x-F)-\frac{1}{2} c E^{2} \\
e & =\arg \max E(1-e) b+e B-\frac{1}{2} d e^{2}
\end{aligned}
$$

The agent's IC constraint is the same as his IC constraint under divisions, (1), above.

The investor participation (IR) constraint is

$$
K \leq(E(1-e)+e)(F-L)+L
$$

where $E_{s u b}, e_{s u b}$ are the anticipated effort choices of $\mathrm{P}$ and $\mathrm{A}$, respectively ${ }^{7}$, in a subsidiary structure. The IR constraint will always bind in equilibrium, since if it did not, $\mathrm{P}$ could raise $\mathrm{K}$ and increase her profit without otherwise affecting the maximization problem.

The first order conditions for the date $\frac{1}{2}$ effort decisions are

$$
\begin{aligned}
E & =\frac{(1-e)(y-F)}{c} \\
e & =\frac{B-E b}{d}
\end{aligned}
$$

Call the solution to these equations $\left(E_{s u b}, e_{s u b}\right)$. The agent's reaction curve is unchanged when we move from divisions to subsidiaries. The effect of the subsidiary debt is that P's reaction curve shifts downward, and this will affect the way $\mathrm{P}$ and $\mathrm{A}$ exert effort in equilibrium, as Lemma 1 illustrates:

Lemma $1 \frac{d E_{s u b}}{d F}<0$ and $\frac{d e_{s u b}}{d F}>0$ : P's effort is decreasing and A's effort is increasing in subsidiary debt.

All proofs are in Appendix A.

The lemma is intuitive: as $\mathrm{F}$ increases, $\mathrm{P}$ is rationally less concerned about having a backup plan for using asset $\mathrm{X}$ if A's effort to develop a new market fails: P's net gain from acquiring

\footnotetext{
${ }^{7}$ More formally, these correspond to the investor's date 0 beliefs about the optimal behavior of $\mathrm{P}$ and $\mathrm{A}$ at date $\frac{1}{2}$, and these beliefs must be correct in equilibrium.
} 
information conditional on A's failure is $y-F$, which is clearly decreasing in $F$. Anticipating that $\mathrm{P}$ will exert less effort, $\mathrm{A}$ exerts more. The agent knows that the likelihood of being "bailed out" by $\mathrm{P}$ is lower when A's effort fails (i.e. using asset X internally, for which A receives the private benefit $b$ ).

It follows from Lemma 1 that P's effort is lower and A's effort is higher under subsidiaries than under divisions. Given that higher F decreases P's effort and increases A's effort, it follows that $E$ is lower and $e$ is higher whenever $\mathrm{P}$ chooses subsidiaries instead of divisions, since divisions are equivalent to subsidiaries without default; i.e. $F \leq L$.

We can substitute the solutions to the IC and IR constraints back into P's date 0 problem:

$$
\max _{F} U_{p}=E_{\text {sub }}\left(1-e_{\text {sub }}\right)(y-L)+e_{\text {sub }}(x-L)-\frac{1}{2} c E_{\text {sub }}^{2}+L
$$

Note that when we substitute in for $K$ using the investor's binding participation constraint, the direct effect of the debt obligation $F$ disappears. Intuitively, $\mathrm{P}$ recovers at date 0 (through the up-front payment $K$ ) the expected value of the payments she must make at date 2. Hence, $F$ affects P's profit only through the indirect effect on the effort levels $E_{s u b}$ and $e_{s u b}$.

Differentiating P's objective with respect to F, we get:

$$
\frac{d U_{p}}{d F}=\frac{d E_{s u b}}{d F}\left(\left(1-e_{s u b}\right)(y-L)-c E_{s u b}\right)+\frac{d e_{s u b}}{d F}\left(x-L-E_{s u b}(y-L)\right)
$$

The expression suggests that there are two competing effects on P's profit from raising $F$. The first term in (3) is the reduction in P's payoff caused by her own reduced incentive for effort at date $\frac{1}{2}$. The second term is the increase in P's profit caused by A's higher effort. When there is an interior solution $F^{*}$ to the first-order condition $\frac{d U_{p}}{d F}=0$ in the range $L<F<y$, it is a maximizer, and a subsidiary with debt $F^{*}$ is the optimal organizational form for the project. If $\frac{d U_{p}}{d F}>0\left(\frac{d U_{p}}{d F}<0\right)$ everywhere in the range $L<F<y$, then a sale (a division) is optimal. We are now ready to analyze comparative statics for the large project case:

Proposition 2 Suppose in a subsidiary, there exists a solution $F^{*}$ between $L$ and $y$ for which $\frac{d U_{p}}{d F}=0$. For a large payoff project, this optimal level of subsidiary debt $F^{*}$ is

a) increasing in $x$ and $B$,

b) decreasing in $y$.

c) $F^{*}$ may be increasing or decreasing in $b$.

P's optimal choice of $F$ balances his own effort incentives against the incentives of the agent. When the payoff from the agent's effort is higher $(x), \mathrm{P}$ responds with higher $F$, since 
this elicits more effort from A. Conversely, when the payoff from P's own effort $(y)$ is higher, $\mathrm{P}$ prefers less debt to preserve her own incentives. When the agent is more self-motivated to run an independent project (higher $B$ ), $\mathrm{P}$ knows that $\mathrm{A}$ will exert more effort, all else equal. This makes the expected payoff from his own effort less valuable at the margin, which leads $\mathrm{P}$ to raise $F$ to further motivate $\mathrm{A}$.

The effect of $b$ on optimal subsidiary debt is ambiguous. On one hand, $b$ has an effect that is the opposite of $B$ : a larger $b$ means that, all else equal, $\mathrm{A}$ is more likely to fail due to weaker incentives. This increases the probability that P's investment matters. Thus, an increase in $b$ may result in $\mathrm{P}$ choosing to focus more on preserving her own incentives by lowering $F$. On the other hand, raising $F$ lowers $E$, which in turn lowers the expected value of the "soft landing" for A. Thus, $\mathrm{P}$ may choose to raise $F$ to focus more on preserving A's incentives by lowering the expected value of the soft landing.

These comparative statics lead to a related result on optimal organizational form:

Corollary 3 Suppose, for some set of parameters, a sale is preferred to any subsidiary (i.e. a subsidiary with any $F, L<F<y$ ). Then a sale is also preferred to any subsidiary if $x$ or $B$ is higher, or $y$ is lower, all else equal. Conversely, if a subsidiary is preferred to a sale for some set of parameters, then a subsidiary is also preferred to a sale if $x$ or $B$ is lower, or $y$ is higher, all else equal.

The next proposition relates to the effect of $b$, the "soft landing" that A realizes when P's project succeeds but A's project does not:

Proposition 4 (Large payoff projects, the effect of a soft landing) For a large-payoff project:

a) If $b=0$, then a division is optimal.

b) If $b>0$, then there exists a subsidiary (with debt $F>L$ ) that is preferred to a division.

c) For b sufficiently close to zero, there exists a subsidiary that is preferred to a sale.

Divisions provide maximal incentives for $\mathrm{P}$ to develop an internal use for asset $\mathrm{X}$. When the project is a large payoff project, A knows that his project will be implemented if his effort is successful. The only downside to placing the project in a division, then, is the weakened incentives for A due to the soft landing provided by P's effort. If $b=0$, this effect disappears. Subsidiary debt would then have the effect of reducing P's effort inefficiently, while having no beneficial effect on A's effort.

If $b>0$, by contrast, there is always some benefit to $\mathrm{P}$ from raising $\mathrm{F}$ slightly above $\mathrm{L}$. The net cost to $\mathrm{P}$ from weakening her own date $\frac{1}{2}$ incentives for effort, caused by raising $F$ 
slightly above $L$, is a second-order effect. This is true because the $E$ that maximizes P's date $\frac{1}{2}$ objective is the same as the $E$ that maximizes P's date 0 objective when $F=L$. But raising $F$ has a first-order effect on A's effort. Hence, a subsidiary that creates a non-zero probability of default is optimal. (It is worth emphasizing, of course, that this result relies on the absence of deadweight bankruptcy costs in default. If bankruptcy costs are realized whenever a default occurs, divisions can be optimal for some $b>0$ because they avoid these costs.)

To summarize the results above, I find that divisions are best at generating incentives for $\mathrm{P}$, while a sale is best for A's incentives. The subsidiary is an organizational form that balances the benefits of a division and a sale. Subsidiaries balance incentive provision for the agent to develop an independent use for the asset (which is strongest in a sale and weakest in a division, due to the "sink or swim" effect) and the preservation of P's incentive to generate an internal use for the asset. As the relative value of A's investment rises relative to P's investment ( $x$ rises relative to $y$ ), or if $\mathrm{A}$ is more self-motivated to run an independent firm (higher $B$ ), $\mathrm{P}$ will focus more on A's incentives. She can do this by increasing the debt level in the subsidiary, or by selling the project entirely.

We now turn to small-payoff projects, which introduces the possibility that $\mathrm{P}$ will interfere with the project preferred by A. Organizational form can be an important tool in mitigating this problem, and thus encouraging A to put more effort into developing an independent use for the assets.

\subsection{Small-payoff projects $(x<y)$}

When P might choose to over-rule A's project, control rights over the project choice can matter. Thus, there are four distinct choices of organizational form (divisions, sale, P-sub and A-sub). The specification of P's problem in a sale is identical to the large-payoff project case above. Similarly, the specification of P's problem in an A-sub is identical to the subsidiary in the large-payoff case; hence. (This is intuitive, because in the A-sub, like the large-payoff case, A's project will be chosen when both $\mathrm{P}$ and $\mathrm{A}$ succeed). We proceed by analyzing divisions and P-subs, and then compare the four organizational forms.

\subsubsection{Divisions}

The principal chooses her effort to maximize 


$$
U_{p} \equiv E y+(1-E) e x+(1-E)(1-e) L-\frac{1}{2} c E^{2}
$$

while the agent maximizes

$$
U_{a} \equiv E b+(1-E) e B-\frac{1}{2} d e^{2}
$$

Taking first order conditions for $\mathrm{P}$ and A, respectively, we get:

$$
\begin{aligned}
E & =\frac{y-L-e(x-L)}{c} \\
e & =\frac{(1-E) B}{d}
\end{aligned}
$$

Notice that, in comparison to the large payoff project, the agent's reaction curve under divisions is lower, since $B>b$. This reflects the agent's loss of initiative that follows from less independence. Knowing that $\mathrm{A}$ will be overruled by $\mathrm{P}$ when both $\mathrm{P}$ and $\mathrm{A}$ succeed, $\mathrm{A}$ exerts less effort, all else equal. At the same time, a given reduction in $\mathrm{P}$ 's effort has a larger positive impact on A's effort in the small payoff project. This is also intuitive, because for small payoff projects, a greater likelihood of an uninformed principal not only reduces A's expected payoff when A fails (the "sink or swim" effect), it also raises A's expected payoff when A succeeds (the "independence" effect). Both effects result in A investing more when $\mathrm{P}$ invests less.

\subsubsection{Prinicipal-controlled subsidiary (P-sub)}

Given the lack of congruence between $\mathrm{P}$ and A under a small payoff project, control of the subsidiary's assets becomes important. When $\mathrm{P}$ controls the assets in the sub, P's date 0 problem is to choose $F, K$ to maximize the following:

$$
\max _{F, K} E(y-F)+(1-E) e(x-F)^{+}-\frac{1}{2} c E^{2}+K
$$

where $E, e$ are the solution to $P$ 's and $A$ 's maximization problems over effort levels at date $\frac{1}{2}$ given $F$, and $K=E_{p s} F+\left(1-E_{p s}\right) e_{p s} \min \{x, F\}+\left(1-e_{p s}\right)\left(1-E_{p s}\right) L$ is the up-front cash infusion from the investor that results in the investor breaking even in equilibrium given $F$ and optimal effort by $\mathrm{P}$ and $\mathrm{A}$. In contrast to the large-payoff case, note that $\mathrm{P}$ may find it optimal to raise $F$ above $x$, which would imply that $P$ prefers to default whenever $A$ 's effort is successful and $P$ 's effort is not. Because we have not introduced bankruptcy costs in this model, this strategy may be optimal for P. She knows that the creditor will receive $x$ in default, and $\mathrm{P}$ captures this expected payoff up-front through higher $K$. 
As in the large-payoff case, the agent's maximization problem is unchanged when we move from a division to a P-sub. Thus, we can solve for the optimal effort levels of $P$ and $A$ :

$$
\begin{aligned}
E & =\frac{y-F-e(x-F)^{+}}{c} \\
e & =\frac{(1-E) B}{d}
\end{aligned}
$$

We can now substitute back in to P's objective, which is solely a function of $\mathrm{F}$ and exogenous parameters:

$$
U_{p}=\max _{F} E_{p s}(y-L)+\left(1-E_{p s}\right) e_{p s}(x-L)-\frac{1}{2} c E_{p s}^{2}+L
$$

Differentiating with respect to $F$, we get $^{8}$ :

$$
\frac{d U_{p}}{d F}=\frac{d E_{p s}}{d F}\left(y-L-e_{p s}(x-L)-c E_{p s}\right)+\frac{d e_{p s}}{d F}\left(1-E_{p s}\right)(x-L)
$$

It is straightforward to show that the equivalent of Lemma 1 also holds in P-subs: $\frac{d E_{s u b}}{d F}<0$ and $\frac{d e_{s u b}}{d F}>0$. With these expressions in hand, we can first show that a modified version of Proposition 2 holds for small-payoff projects in both A-subs and P-subs:

Proposition 5 Suppose in an A-sub or a P-sub there exists a unique solution $F^{*}$ between $L$ and $y$ for which $\frac{d U_{p}}{d F}=0$. For a small payoff project, this optimal level of subsidiary debt $F^{*}$ is

a) increasing in $x$ and $B$, and

b) decreasing in $y$.

c) In an A-sub, $F^{*}$ may be increasing or decreasing in b. In a P-sub, $F^{*}$ is independent of $b$.

We can now compare organizational forms, starting with the effect of the soft landing on the optimal choice:

Proposition 6 (Small payoff projects, the effect of the soft landing) For small-payoff projects,

a) For any $b \geq 0$, there exists a P-sub (with $F>L$ ) that is preferred to a division.

b) For b sufficiently close to zero, there exists an A-sub that is preferred to a sale.

\footnotetext{
${ }^{8}$ This is a slight abuse of notation, since this expression is not differentiable at $F=x$.
} 
Part (a) of the proposition stands in contrast to the large-project case above, in which divisions are optimal for $b=0$. In the small project case, this is no longer true: divisions continue to weaken A's incentive for effort, even if $b=0$, due to a lack of independence. The proposition says that P-subs are always preferred to divisions in this case, because increasing $F$ above $L$ by a small amount has only a second-order effect on P's net payoff from her own effort, and a first-order effect on profit from $A$ 's effort.

Part (b) of the proposition is analogous to part (c) of Proposition 4 above, but the result holds only for A-subs, not for P-subs. Both the A-sub and the sale give the agent complete autonomy, so there is no difference between the two ownership structures when $A$ 's effort succeeds. The difference between the A-sub and the sale is that a sale provides sharper incentives to the agent than the A-sub through the "sink or swim" effect when $A$ fails: under the A-sub, the agent knows he may be rehired internally when his effort fails and P's effort succeeds. As $b$ approaches 0 , the effect of this safety net becomes negligible to $A$. Hence, the A-sub dominates the sale, because $\mathrm{P}$ avoids a holdup problem: she maintains the option to reabsorb the sub, thus preserving the internal value of her investments. In the small project case, a P-sub does not dominate a sale as $b$ approaches 0 , because a sale provides $A$ with autonomy, while a P-sub does not.

Our next proposition relates to the trade-offs in allocating control in a subsidiary:

Proposition 7 The optimal allocation of control over a subsidiary depends on the relative strength of preferences over actions when both $P$ and $A$ succeed:

a) For b sufficiently close to B, the optimal P-sub is preferred to the optimal A-sub.

b) For $x$ sufficiently close to $y$, the optimal A-sub is preferred to the optimal P-sub.

The A-sub is a way to fix A's loss of initiative that would occur due to A's lack of independence. When $\mathrm{P}$ has control over the use of asset $\mathrm{X}$, she may generate a successful idea and choose to use $\mathrm{X}$ internally. Giving A decision rights gives A greater incentive to generate information, because he receives a higher payoff from acquiring information. But as $b$ approaches $B$, the initiative effect of the A-sub goes to zero: A becomes indifferent to whether $\mathrm{P}$ or $\mathrm{A}$ has control rights over the use of $\mathrm{X}$. Control rights continue to matter for $\mathrm{P}$, however, because $y>x$. Thus, it becomes optimal for $\mathrm{P}$ to keep control when $b$ is sufficiently close to $B$.

The second half of the proposition is the flip side of the previous result. Intuitively, as $x$ approaches $y$, control rights matter more to A than to $\mathrm{P}$. Delegating decision rights to A increases A's initiative at low cost to P. 


\section{Extensions}

This section is very incomplete: I suggest some possible interpretations and extensions of the basic model and some speculation about potential results. Suggestions on these topics or others are most welcome.

\subsubsection{Incentive-based compensation}

In the previous section, I relied on private benefits as the exclusive source of incentives for the agent. Suppose, instead, that $\mathrm{P}$ and $\mathrm{A}$ can write incentive pay contracts that attempt to tie A's payoff to the value of her effort. In this section I show that incentive pay in a multi-unit firm will not provide a complete substitute for subsidiary debt as a means of encouraging innovation by $\mathrm{A}$ at lowest cost to $\mathrm{P}$. While I will allow contracts to be made contingent on the payoff of the project that is chosen, I will assume that a court cannot verify the potential payoff of the project that is not chosen.

For concreteness, suppose that $x<y$, so that the independence effect is relevant to $\mathrm{P}^{9}$

If asset $\mathrm{X}$ is placed in a $\mathrm{P}$-sub, $\mathrm{P}$ 's date 0 problem is

$$
\max _{w, F, K} E(y-F)+(1-E) e(x-w-F)-\frac{1}{2} c E^{2}+K
$$

As in the private benefits case, the problem is simplified somewhat: it restricts consideration to $F>L$ without loss of generality. It also restricts consideration to contracts that pay $A$ only when $A$ 's project is implemented; it will never be in $\mathrm{P}$ 's interest to pay $A$ when $P$ 's project is chosen, as this will merely reduce A's incentive to generate an independent project.

The maximization is subject to the IC constraints for $\mathrm{P}$ and $\mathrm{A}$ at date $\frac{1}{2}$ :

$$
\begin{aligned}
E & =\arg \max E(y-F)+(1-E) e(x-w-F)-\frac{1}{2} c E^{2} \\
e & =\arg \max E b+(1-E) e(B+w)-\frac{1}{2} d e^{2}
\end{aligned}
$$

and the investor's participation constraint binds as before: $K=(E+(1-E) e)(F-L)+L$. The first-order conditions for $\mathrm{P}$ and $\mathrm{A}$ at date $\frac{1}{2}$ are

$$
\begin{aligned}
E & =\frac{y-F-e(x-w-F)}{c} \\
e & =\frac{(1-E)(B+w)}{d}
\end{aligned}
$$

\footnotetext{
${ }^{9}$ Parameter assumptions also must be modified slightly to force interior solutions for $E$, $e$ :here, I assume $d>B+x$, so that there is no $w$ that will result in $e>1$.
} 
Assuming a unique, stable solution $\left(E_{s u b}, e_{s u b}\right)$ to the first order conditions above, we can substitute in, along with the binding investor participation constraint, to get

$$
\max _{w, F} U_{p}=E_{s u b}(y-L)+\left(1-E_{s u b}\right) e_{s u b}(x-w-L)+L-\frac{1}{2} c E_{s u b}^{2}
$$

The partial derivatives of $U_{p}$ with respect to $F$ and $w$ are

$$
\begin{gathered}
\frac{\partial E_{s u b}}{\partial F}\left(y-L-e_{s u b}(x-w-L)-c E_{s u b}\right)+\frac{\partial e_{s u b}}{\partial F}\left(1-E_{s u b}\right)(x-w-L) \\
\frac{\partial E_{s u b}}{\partial w}\left(y-L-e_{s u b}(x-w-L)-c E_{s u b}\right)+\frac{\partial e_{s u b}}{\partial w}\left(1-E_{s u b}\right)(x-w-L)-\left(E_{s u b}+\left(1-E_{s u b}\right) e_{s u b}\right)
\end{gathered}
$$

Note that the partial derivative of profit with respect to wages and subsidiary debt is similar, except for the term $E_{s u b}+\left(1-E_{s u b}\right) e_{s u b}$, the increase in P's expected wage bill when $w$ rises. This term is not present when we change $F$, because any increase in $F$ is recouped up front through a higher $K$. In contrast to managerial compensation, which must be given away to the agent due to his limited wealth, the investor can be required to pay ex-ante for any expected payment he receives ex-post.

In this modified model, it is possible to demonstrate that a result in Proposition 6 continues to hold: namely, that there always exists a subsidiary with $F>L$ that is preferred to a division, even when $w$ is set optimally. Unlike raising $w$, which is always costly to $\mathrm{P}$, it is possible to raise $F$ slightly above $L$ and generate more effort by A at minimal expense to $\mathrm{P}$. Thus, the model's main conclusion, that subsidiaries are valuable tools for incentivizing unit managers remains robust to the inclusion of incentive pay.

\subsubsection{Multi-tasking for $\mathbf{P}$}

Instead of interpreting P's effort cost as a disutility from working, it can also be recast as an opportunity cost to $\mathrm{P}$ of investing in its other projects. In this sense, placing $\mathrm{X}$ in a subsidiary can be seen as a way of not only increasing A's initiative to develop the innovation as an independent project, but also as a way of encouraging $\mathrm{P}$ to focus on its core business.

\subsubsection{When Subsidiaries Don't Work}

An important assumption in the structure of the model is that A's project requires only asset $\mathrm{X}$, and that P's core business (the large, certain cash flow) requires only asset Y. Suppose, 
instead, that P's core business also requires asset X. In this case, subsidiaries won't work as a means of credibly committing to independence for $\mathrm{A}$. If $\mathrm{P}$ puts asset $\mathrm{X}$ in the sub, then subs are equivalent to divisions: $\mathrm{P}$ cannot credibly commit to reducing $E$ because she always has the incentive to pay off the creditor and keep asset X. In this sense, subsidiaries only create independence for unit managers to the extent that the new project requires assets that can be credibly abandoned to creditors.

A different set of problems may arise if A's project also requires both $\mathrm{X}$ and $\mathrm{Y}$. For instance, suppose that an A-sub is optimal given the parameter values in the model (recall that this occurs when $y>x$ but $y-x$ is small). A decision to grant A control over project choice may require that the subsidiary owns both assets; otherwise, $\mathrm{P}$ can withhold the use of asset $\mathrm{Y}$. But if $\mathrm{X}$ and $\mathrm{Y}$ are both owned by the subsidiary, $\mathrm{P}$ cannot credibly commit to reducing $E$, as above.

\subsubsection{Bankruptcy Costs When the Subsidiary Defaults}

As noted in the main text, if default on subsidiary debt carries deadweight bankruptcy costs, then it is straightforward to show that P's decision of optimal organizational form will tilt away from subsidiaries, and toward divisions or sales. In particular, a division may be optimal, for small or large payoff projects, even if $b>0$. The deadweight costs of bankruptcy, which are realized when both $\mathrm{P}$ and $\mathrm{A}$ fail, will result in lower creditor recovery, which will hurt $\mathrm{P}$ through lower $K$.

\subsubsection{Liquidity Constraints and Risk in the Core Business}

In the base model, the existing project produces a large, certain cash flow, and $\mathrm{P}$ is not liquidity constrained. Suppose, instead, that the existing project requires financing and/or is risky, so that $\mathrm{P}$ might bear some default risk. Placing $\mathrm{X}$ in a subsidiary may affect A's effort through other channels. For example, borrowing through the subsidiary limits the possibility that asset $\mathrm{Y}$ is put at risk of seizure when A's project fails. Under a divisional structure, $\mathrm{P}$ has more incentive to interfere in A's project, so as to protect asset Y. Conversely, since subsidiaries also create asset partitioning (Hansmann and Kraakman 2000) the subsidiary also protects A's incentive compensation from interference by P's creditors. If the new project is a division, A's promised wage might share pro-rata with P's creditors in a default. If there is a risk that A's compensation will not be available due to the claims of P's creditors, A may exert less effort: this is another mechanism by which the subsidiary can increase A's initiative. 


\section{Conclusion}

To be written.

\section{References}

Aghion, P. and J. Tirole. 1987. Formal and Real Authority in Organizations. Journal of Political Economy 105:1-29.

Bolton, P. and D. S. Scharfstein. 1990. A Theory of Predation Based on Agency Problems in Financial Contracting. American Economic Review 80:93-106. . 1996. Optimal Debt Structure and the Number of Creditors. Journal of Political Economy 104:1-25.

Christensen, C. 1997. The Innovator's Dilemma: When New Technologies Cause Great Firms to Fail. Harvard Business School Press.

Christensen, C. and M. Raynor. 2003. The Innovator's Solution: Creating and Sustaining Successful Growth. Harvard Business School Press.

Grossman, S. and O. Hart. 1986. The Costs and Benefits of Ownership: A Theory of Vertical and Lateral Integration. Journal of Political Economy, 94: 691-719.

Harford, J. 2011. Adapt: Why Success Always Starts with Failure. Farrar, Straus and Giroux.

Hart, O. and J. Moore. 1994. A Theory of Debt Based On the Inalienability of Human Capital. Quarterly Journal of Economics 109:841-879.

\section{Appendix A: Proofs}

Lemma 1:

If we substitute P's FOC into the FOC for $\mathrm{A}$, we get

$$
\begin{aligned}
E_{\text {sub }} & =\frac{(d-B)(y-F)}{c d-b(y-F)} \\
e_{\text {sub }} & =\frac{B c-b(y-F)}{c d-b(y-F)}
\end{aligned}
$$


Differentiating with respect to $\mathrm{F}$ and rearranging, we get

$$
\begin{aligned}
\frac{d E_{\text {sub }}}{d F} & =\frac{-c d(d-B)}{(c d-b(y-F))^{2}} \\
\frac{d e_{s u b}}{d F} & =\frac{b c(d-B)}{(c d-b(y-F))^{2}}
\end{aligned}
$$

We have assumed that $c>y-L \geq y-F$ and $d>B \geq b$, so the denominator of both expressions $(c d-b(y-F))^{2}$ is always strictly positive. Given our assumption that $d>B$, it is evident by inspection that $\frac{d E_{s u b}}{d F}<0$ and $\frac{d e_{s u b}}{d F}>0$.

Proposition 2:

If an $F^{*}$ exists that solves $\frac{d U_{p}}{d F}=0$, it is given by $F^{*}=\frac{b(c d-b y)(x-L)+(d-B)(L c d-b y(y-L))}{(c d-b(y-L))(d-B)-b^{2}(x-L)}$. The proof simply requires analyzing the partial derivative with respect to the variable of interest for any $L<F^{*}<y$. Algebraic manipulation reveals that $F^{*}<y$ iff $b(x-L)<(d-B)(y-L)$ and $L<F^{*}$ iff $(c d-b(y-L))(x-L)>(d-B)(y-L)^{2}$.

a) $\frac{\partial F^{*}}{\partial x}>0$ is straightforward and thus omitted. Rearranging the expression for $\frac{\partial F^{*}}{\partial B}$, it can be shown that $\frac{\partial F^{*}}{\partial B}>0$ iff $c d>2 b(y-L)$. This condition holds whenever $L<F^{*}<y$, using the inequalities above.

c) Rearranging $\frac{\partial F^{*}}{\partial y}$, (proof completed but not yet written)

Corollary 3:

A necessary and sufficient condition for a subsidiary with $L<F<y$ to be preferred to a sale is $\frac{d U}{d F}<0$ at $F=y$. Substituting in to (3), it can be shown that this is true if and only if $b(x-L)<(d-B)(y-L)$. When a sale is optimal this condition will fail. By inspection, if $b(x-L) \geq(d-B)(y-L)$ for a given set of parameters, it will also hold as $x$ or $B$ rises, and as $y$ falls. Conversely, if $b(x-L)<(d-B)(y-L)$, for a given set of parameters, the inequality will also hold for lower $x$ and $B$, and higher $y$.

Proposition 4:

When $b=0$, the first-order condition for optimal $e$ is $e=\frac{B}{d}$, under a sale, a subsidiary, and a division. Hence, A's effort is the same for all organizational forms and $\frac{d e}{d F}=0$. Under subsidiaries, then, $\frac{d U_{p}}{d F}$ reduces to $\frac{d E_{s u b}}{d F}\left(\left(1-e_{s u b}\right)(y-L)-c E_{s u b}\right)$. The first order condition for optimal effort by $\mathrm{P}$ is $\left(1-e_{\text {sub }}\right)(y-F)-c E_{\text {sub }}=0$. Since $F>L,\left(1-e_{\text {sub }}\right)(y-L)-c E_{\text {sub }}>0$ and $\frac{d E_{s u b}}{d F}<0$ by Lemma 1 . Hence $\frac{d E_{s u b}}{d F}\left(\left(1-e_{s u b}\right)(y-L)-c E_{s u b}\right)<0$ and a division is optimal.

When $b>0$, consider P's utility at $F=L$ (which is equivalent to a division). In this case, the FOC for $\mathrm{E}$ at date $\frac{1}{2}$ is $\left(1-e_{\text {sub }}\right)(y-L)-c E_{\text {sub }}=0$. This implies that the expression for $\frac{d U_{p}}{d F}$ reduces to $\frac{d U_{p}}{d F}=\frac{d e_{s u b}}{d F}\left(x-L-E_{s u b}(y-L)\right)$. Since $\frac{d e_{s u b}}{d F}>0$ by Lemma $1, \mathrm{P}$ 's utility is 
increasing in $F$ at $F=L$, implying that there exists a subsidiary with $F>L$ that is preferred to a division.

Proposition 5: To be completed.

Proposition 6:

a) As before, this uses an envelope theorem argument. In a P-sub with $F=L, \frac{d U_{p}}{d F}$ collapses to $\frac{d e_{p s}}{d F}(1-E)(x-L)$ because the FOC for optimal effort is $\left(1-e_{a s}\right)(y-L)-c E_{a s}=0$. $\frac{d e_{p s}}{d F}\left(1-E_{p s}\right)(x-L)$ is always strictly positive because $\frac{d e_{p s}}{d F}>0$.

b) If asset $\mathrm{X}$ is sold, $\mathrm{P}$ 's utility is $U_{p}^{\text {sale }}=e_{s} x+\left(1-e_{s}\right) L$, where $e_{s}$, where $e_{s}=\frac{B}{d}$. Under an A-sub, P's utility is $U_{p}^{a s u b}=E_{a s}\left(1-e_{a s}\right)(y-L)+e_{a s}(x-L)-\frac{1}{2} c E_{a s}^{2}+L$. As $b$ approaches 0 , $e_{a s}$ converges to $e_{s}$. So the difference in P's utility between the A-sub and the sale converges to

$$
U_{p}^{a s u b}-U_{p}^{\text {sale }}=E_{a s}\left(1-e_{a s}\right)(y-L)-\frac{1}{2} c E_{a s}^{2}
$$

Note that $E_{a s}$ is the $E$ that maximizes this expression, and the value of this expression is always strictly positive, since the marginal cost of effort is zero when $E=0$, while the marginal benefit of effort $\left(1-e_{a s}\right)(y-L)$ is positive and bounded away from zero.

\section{Proposition 7:}

Part (a): As $b$ converges to $B$, A's reaction curve for the A sub and the $\mathrm{P}$ sub will converge. That is, for a given choice of E, whether in a P-sub or an A-sub, A's best response converges to the same value of $e$. Consider some $F<y$ that is optimal for $\mathrm{P}$ in an A-sub (call this $F_{a}^{*}$ ). For any such $F_{a}^{*}$, we can find an $F_{p}^{*}>F_{a}^{*}$ for which P's optimal choice of $\mathrm{E}$ is the same in the $\mathrm{P}$-sub with debt $F_{p}^{*}$ and the A-sub with debt $F_{a}^{*}$. It is always possible to find such an $F_{p}^{*}<y$, because E's reaction curve is higher under the P-sub than under the A-sub, E is continuous and decreasing in $\mathrm{F}$, and becomes zero at $F=y$. So $E$, e, and $g(E)$ are arbitrarily close in the A-sub with debt $F_{a}^{*}$ the and P-sub with debt $F_{p}^{*}$. But P's utility is higher under this P-sub, because she receives $y$ instead of $x$ when both $\mathrm{P}$ and $\mathrm{A}$ succeed. So we have shown that there is always some $F$ for which P's utility is higher than the her maximum utility under an A-sub. A fortiori, her utility is higher under the optimal $\mathrm{F}$ in a P-sub.

Part (b): The argument is qualitatively the same as in part (a). To be completed. 